ISSN 2413-0877 Volume 2 (2015) 371

The 3rd International Conference on Biological Science 2013

(The 3rd ICBS-2013)

\title{
POTENTION OF GENISTEIN (4', 5, 7-TRIHYDROXY ISOFLAVONE) \\ ON SPERMAZOA'S MORPHOLOGY AND VIABILITY OF BALB/C STRAIN MOUSE (Mus musculus)
}

\author{
Ervina Wijayanti ${ }^{1}$, Umie Lestari² $^{2}$ Nursasi Handayani ${ }^{2}$ \\ ${ }^{1}$ Student of Biology Department, Faculty of Mathematic and Science, State University of Malang, \\ Malang Indonesia \\ ${ }^{2}$ Lecturer of Biology Department, Faculty of Mathematic and Science, State University of Malang, \\ Malang Indonesia \\ E-mail: ervina.wj@gmail.com
}

\begin{abstract}
Genistein (4', 5, 7-trihydroxy isoflavone) is one of phytoestrogen compounds, from isoflavone groups that's abudance in leguminaceae plants and its food products. There are lack and different reports about genistein's effect to the male reproduction system, although Genistein is one of very familiar compounds in widely consumed foods. The aim of this research is exploring Genistein's effect to the male reproduction system as specially spermatozoa's morfology and viability. This research use 24 male mice strain Balb/C, 8 to 10 weeks old that's devided into 4 treatments and 6 repetitions. Each mouse is gavaged using Genistein that is dissolved in corn oil for 36 days based on its dosage group treatments $(0 ; 3,5 ; 4,2 ;$ and $4,9 \mathrm{mg} / \mathrm{kg} \mathrm{bw} /$ day). Sperm slide made from sperm suspention, colored by modification of eosin-nigrosin coloring method based on WHO. Persentage of spermatozoa's normal-abnormal morphology and viability are calculated using One Way Anova and continous by 5\% Least Significant Difference (LSD). This research show that Genistein has bad effects in male reproduction system, and seems like a strong disruptor for spermatozoa. It significantly influence to spermazoa's morphology and viability of Balb/C mouse (Mus musculus). Genistein begins to influence at lowest dosage, $3,5 \mathrm{mg} / \mathrm{kg}$ bw for both of viability and morphology. It significantly decrease viability at $4,2 \mathrm{mg} / \mathrm{kg}$ bw dosage, and increase abnormal morphology of spermatozoa at 4,9 mg/kg bw dosage. Morphology abnormalities that occurs in this research include head and tale abnormalities, or combination of both.
\end{abstract}

Key words: Genistein, Spermatozoa Morphology, Spermatozoa Viability, Mouse

ISSN 2413-0877 (C) 2015 The Authors.

Published by KnowledgeE Publishing Services This is an open access article under the CC BY-NC-ND license (http://creativecommons.org/licenses/by-nc-nd/4.0)

Selection and Peer-review under responsibility of the 3rd ICBS-2013

Doi http://dx.doi.org/10.18502/kls.v2i1.178 